\title{
Student Engagement in a Flipped Secondary Mathematics Classroom
}

\author{
Mustafa Cevikbas $^{1} \cdot$ Gabriele Kaiser $^{1,2}$ (D)
}

Received: 8 July 2020 / Accepted: 21 August 2021 / Published online: 4 September 2021

(c) The Author(s) 2021, corrected publication 2022

\begin{abstract}
Many students are becoming increasingly disengaged in school, particularly in mathematics. This is an important problem as lack of engagement may threaten students' achievement and performance in mathematics. A flipped learning pedagogy, which encourages students to take an active role in learning mathematics, has become a widely researched topic in recent years. However, few empirical studies to date have focused on the influence of flipped learning on student engagement in secondary mathematics classrooms. This qualitatively oriented study aimed to extend existing research on the role of flipped learning in behavioral, cognitive, and emotional engagement by adopting a social constructivist perspective to examine a secondary mathematics classroom. The participants were 33 high school students and their mathematics teacher, from whom data were gathered using multiple empirical methods. The results indicate that a flipped learning pedagogy has the potential to play a positive role in behavioral, cognitive, and emotional engagement as it provides learners with many possibilities for the learning of mathematics. However, to successfully flip learning, it is important to have a well-developed interactive design and to encourage social interaction in mathematics teaching and learning. Engagement was found to be negatively affected when the students had a negative perception of flipped learning and failed to complete the pre-class tasks. Overall, our results indicate that mathematics education can benefit from a flipped learning pedagogy as it has the potential to strengthen students' engagement and mathematics learning in a social environment.
\end{abstract}

Keywords Behavioral engagement · Cognitive engagement · Emotional engagement $\cdot$ Flipped classroom $\cdot$ Flipped learning $\cdot$ Student engagement

Gabriele Kaiser

gabriele.kaiser@uni-hamburg.de

Mustafa Cevikbas

mustafa.cevikbas@uni-hamburg.de

1 Universität Hamburg, Von-Melle-Park 8, 20146 Hamburg, Germany

2 Institute for Learning Sciences and Teacher Education, Australian Catholic University, Brisbane, Australia 


\section{Introduction}

Engagement is predictive of students' achievement, grades, and high school dropout rate, and as a result, it plays a critical role in students' future careers (Christenson et al., 2012). It is defined as "the student's psychological investment in and effort directed toward learning, understanding, or mastering the knowledge, skills, or crafts that academic work is intended to promote" (Newmann, 1992, p. 12). Although it is known that engagement is important for learning (Fredricks et al., 2004), there has been little research on the promotion of student engagement in mathematics. A large number of students are becoming disengaged in mathematics as they proceed from primary to lower and then to upper secondary school. Indeed, some studies indicate that 40-60\% students (not including dropouts) from urban, suburban, and rural areas are disengaged (Collie et al., 2019; Marks, 2000; Martin et al., 2015). Collie et al. (2019) reported that this problem is increasing in many countries, including the USA, Australia, Finland, and France. As there is a strong relationship between mathematics achievement and engagement, the erosion of engagement may threaten students' achievement and performance in secondary mathematics classrooms (Fredricks et al., 2016; Schuetz et al., 2018).

The importance of engagement in learning and the existence of engagement problems in mathematics motivated this study's focus on the promotion of students' engagement in mathematics classrooms. Specifically, the research was intended to examine flipped learning (FL) as an alternative approach for students to engage in learning mathematics. This innovative approach is defined as one in which "events that have traditionally taken place inside the classroom now take place outside the classroom and vice versa" (Lage et al., 2000, p. 32). In other words, the core strategy of FL is to move lecturing activities outside the classroom and maximize class hours for active learning activities. Students can access manifold learning materials (e.g. videos, podcasts, slides, books, journal articles, or notes) outside of class hours, during which time they can communicate and interact with their teachers and peers. This learning is reinforced by in-class learning activities guided by the teacher (Cevikbas \& Kaiser, 2020; Lo $\&$ Hew, 2017). An FL structure can support students in achieving crucial goals related to mathematics learning (e.g. reasoning, inquiry, argumentation, conjectures and deductions, deep learning, creative thinking, cognitive continuity, and problem-solving) that are not easy to achieve with traditional learning structures due to time constraints (Bergmann \& Sams, 2012; Cevikbas \& Kaiser, 2021). According to Kuiper et al. (2015), even if FL does not directly ensure students' learning outcomes, it provides additional time for well-designed activities that allow students to gain a conceptual understanding of new topics. In other words, FL can provide students with more flexibility and opportunities to construct their own knowledge and actively engage in the learning process, which is crucial since active engagement can contribute to better learning and understanding (Marks, 2000).

Although numerous studies have focused on engagement from a psychological perspective, few studies have been conducted on student engagement in flipped 
mathematics classrooms (Clark, 2015; Muir, 2017; Steen-Utheim \& Foldnes, 2018). In addition to the lack of focus on engagement in mathematics classrooms, there are gaps in the literature in terms of conceptual and methodological considerations related to engagement in flipped learning settings (see meta-analysis by Bredow et al., 2021). Many studies highlight that different dimensions of student engagement in flipped mathematics classrooms have been insufficiently examined (Cevikbas \& Kaiser, 2020; Lo \& Hew, 2017; Muir, 2017). Recent studies indicate that future studies should focus on FL, especially in secondary education, and should examine indicators of engagement more broadly (Bond, 2020; Lo \& Hew, 2017). Most FL studies conducted in the context of mathematics education examine engagement from motivational perspectives (e.g. self-determination theory) and use predominantly mixed-method and quantitative research methods (Bond, 2020; Steen-Utheim \& Foldness, 2018). Thus, it is necessary to conduct qualitative studies that are motivated by different grand theories to expand the existing knowledge of engagement in FL settings. Due to the limited nature of research and existing discourse, the relationship between engagement (behavioral, emotional, and cognitive) and FL has not been conclusively examined (Bond, 2020; Hodgson et al., 2017).

To address these research gaps, the current qualitatively oriented research study separately investigates the behavioral, emotional, and cognitive engagement of 10th-grade students in flipped and non-flipped mathematics classrooms using a variety of engagement indicators. The study adopts a social constructivist perspective, which is especially appropriate for capturing students' point of view. From this perspective, the following research questions (RQs) are addressed: (1) How was mathematics teaching enacted with an FL approach as compared to a non-FL approach? (2) How did 10th-grade students' engagement differ for mathematics taught with an FL approach as compared to a non-FL approach?

\section{Conceptual and Theoretical Background}

In this section, we outline the conceptual and theoretical foundations of the study and establish the current state of knowledge about engagement when an FL approach is applied in secondary mathematics education. In addition, we explain how this study fits into the existing literature and what contributions the study offers.

\section{Conceptualization of Engagement}

The highly cited paper by Fredricks et al. (2004) defines engagement as a metaconstruct that includes behavioral, cognitive, and emotional engagement, which are closely interrelated. In the current study, we approached student engagement from Fredricks et al.'s (2004) perspective and adopted their definition. According to this conceptualization, behavioral engagement requires effort and participation in social, academic, and extracurricular activities; furthermore, it is critical for the attainment of positive academic outcomes and prevention of dropout. Disruptive behaviors are 
seen as an indicator of behavioral disengagement. Cognitive engagement is characterized by "investment," meaning consideration and eagerness to understand complicated ideas and master challenging skills. Emotional engagement involves students' positive and negative reactions to their peers, teachers, and school, and it promotes eagerness to study.

Empirical research necessitates that the construct of engagement is conceptualized and that the dimensions and indicators of engagement examined empirically are made explicit (Appleton et al., 2008; Bond, 2020; Christenson et al., 2012). Bond (2020) highlights that a significant majority of studies do not include a definition of engagement, while most studies tend to approach engagement from a behavioral perspective as active participation and interaction with learning and content, staying on task, and investment of effort. She reports that a limited number of studies approach engagement from an emotional and/or cognitive perspective. Therefore, a more inclusive approach to the study of engagement is required.

\section{Measurement Issue of the Engagement}

Engagement is not a distinct theoretical construct, and it is difficult to measure precisely. However, several approaches to measuring engagement have been developed. According to Chapman (2003), student engagement can be measured through selfreport questionnaires, checklists and rating scales, work sample analyses, direct observations, and focused case studies. Bond (2020) reports that surveys are the most frequently used method to measure engagement in FL studies and, qualitative approaches are rarely used to measure engagement. The majority of studies on engagement with an FL approach have attempted to measure engagement based on self-report instruments and data (Hodgson et al., 2017). However, engagement cannot be simply reduced to measurable items on surveys (O'Flaherty \& Phillips, 2015). Additionally, self-report instruments may prompt validity-related concerns (Hodgson et al., 2017). Alternative approaches to measuring engagement are to gather data from teacher reports and to apply observation strategies. However, these also raise concerns; for example, observational measures provide limited information about the intrinsic aspects of emotional and cognitive engagement (Fredricks et al., 2004). Thus, it is recommended to use different data sources and multiple data collection methods to measure engagement. It is also ideal to ensure a balance between self-reported data and non-self-reported data, as this might be useful to draw accurate conclusions about student engagement.

\section{Student Engagement in Flipped Mathematics Classrooms at Secondary Level}

Within the current discourse on FL, ample studies focus on teaching and learning in flipped mathematics classrooms. However, only a few specifically address student engagement in the context of secondary mathematics education and compare FL to non-FL approaches. More importantly, there is a lack of research that objectively examines student engagement in the context of FL at the secondary level by focusing on each component of engagement, including behavioral, cognitive, and 
emotional aspects (Hodgson et al., 2017; Lo \& Hew, 2020). On the one hand, most researchers see engagement as a whole entity (Hodgson et al., 2017; Muir, 2017; Muir \& Geiger, 2016) and do not examine the different dimensions of engagement in depth. On the other hand, some researchers focus on only one dimension of engagement in FL, such as cognitive engagement (Lo \& Hew, 2020) or behavioral engagement (Hodgson et al., 2017).

Although most existing studies approach engagement from the motivational perspective (e.g. Lo \& Hew, 2020; Muir, 2017; Muir \& Geiger, 2016), others do not mention which analytical and theoretical frameworks they use (e.g. Clark, 2015; Hodgson et al., 2017). Some researchers (e.g. Lo \& Hew, 2020; Muir, 2017; Muir \& Geiger, 2016) support students' mathematics learning by using the conceptualization of FL proposed by the Flipped Learning Network (FLN) and the first principle of instruction design theory. Lo and Hew (2020) design an FL with gamification and employ self-determination theory to support students' cognitive engagement. Similarly, Muir (2017) draws upon self-determination theory to examine whether students' autonomy, relatedness, and competence are met in FL.

All the studies mentioned above conducted mixed-method research. Most measured engagement through surveys and compared FL and non-FL in light of the survey results. There is a lack of qualitative research investigating student engagement in depth, particularly with regard for its dimensions, in flipped secondary mathematics classrooms. In addition, research needs to use a wealth of engagement indicators to extend the knowledge on engagement in FL.

The majority of existing research found FL to be a promising approach to promote engagement. The results of the study by Lo and Hew (2020) indicate that students in an FL classroom with gamification significantly outperformed those taught with a non-FL approach (lecture-based teaching and online teaching). The results suggest that students in FL classrooms had a higher level of cognitive engagement, which "refers to the motivation to master one's pursuits of learning; this includes the desire to exceed course requirements, and a preference for challenges" (Lo \& Hew, 2020, p. 472). Similarly, Muir and Geiger's (2016) and Muir's (2017) results indicated that FL promoted students' engagement in mathematics at secondary level and that students positively perceived their FL experiences, "with the results indicating that it met their needs for competence, autonomy, relatedness, and relevance" (Muir, 2017, p. 287). Clark (2015) also found that FL has positive effects on engagement, especially during classroom activities. Additionally, Hodgson et al. (2017) sought to assess behavioral engagement in three pre-college settings using observational instruments, but they found that FL interventions did not increase behavioral engagement more than lecture-based instruction, contrary to commonly reported results.

The current state of the literature illustrates that student engagement in FL is under-researched and under-theorized (Abeysekera \& Dawson, 2015), especially for secondary mathematics education (Bond, 2020; Hodgson et al., 2017; Lo \& Hew, 2020). The current study expands the research in this field by investigating students' engagement in FL in secondary education and incorporating the students' perspective. Unlike existing research, this study (1) employed an interactive FL design and applied an empirically robust conceptualization of engagement; (2) utilized a variety 
of engagement indicators, with multiple data collection methods and sources, and qualitatively measured student engagement in depth; (3) used social constructivist theory as a lens to investigate student engagement in FL from the student perspective; and (4) separately focused on behavioral, cognitive, and emotional engagement in FL and non-FL settings.

\section{Theoretical Framework}

FL has become a well-known pedagogy in the last decade, although no consensus on a particular definition or understanding of the concept has yet been reached. Most studies that focus on FL present it as a student-centered pedagogy in which in-class activities and tasks from traditional approaches are substituted by out-of-class activities (Cevikbas \& Argün, 2017). A group of researchers from FLN offers the following definition:

FL is a pedagogical approach in which direct instruction moves from the group learning space to the individual learning space, and the resulting group space is transformed into a dynamic, interactive learning environment where the educator guides students as they apply concepts and engage creatively in the subject matter. (FLN, 2014)

In accordance with this conceptualization, teachers should integrate the following four pillars of FL into their teaching:

(1) Flexible environment: Teachers can create flexible learning environments to support both group work and individual studies, and students can decide where and when they learn in an interactive way.

(2) Learning culture: FL, as a student-centered approach, creates opportunities for inquiry, meaningful learning, collaboration, socialization, and active engagement.

(3) Intentional content: Teachers determine what content students should learn and what materials they can discover independently.

(4) Professional educator: Teachers consistently guide their students and give them timely feedback and scaffolding before assessing their work using dynamic assessment approaches.

Teachers can foster interaction, communication, and collaboration, and they can welcome constructive criticism in flipped classrooms to improve their teaching. Due to the relevance of research studies' conceptualization of FL, it is important to emphasize that this study applies the definition of FL proposed by FLN (2014). This conceptualization of FL aligns with the social constructivist approach and its theoretical requirements, and it enhances the objectives of the present study.

FL highlights the value of the social context for acquiring cognitive information, providing students with more opportunities to engage in learning mathematics. As a reform-oriented educational pedagogy, FL is strongly connected to Vygotsky's (1978) ideas. It is also connected to the concept of social constructivism (Ahmed, 
Fig. 1 Theoretical framework of the flipped classroom

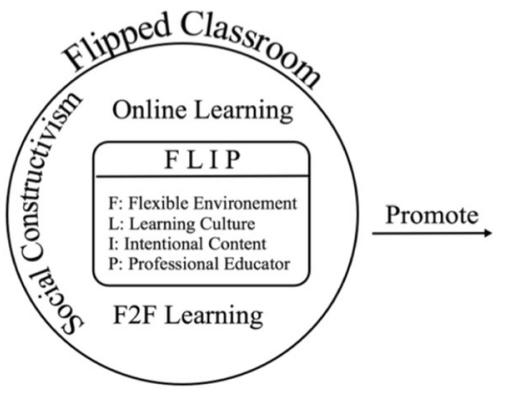

Student Engagement

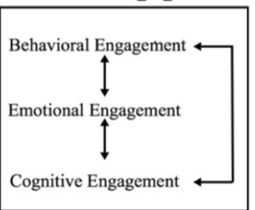

2016; Cevikbas \& Kaiser, 2020; Steen-Utheim \& Foldness, 2018), as it has significant potential to promote active engagement in mathematics (Bergmann \& Sams, 2012; Cevikbas \& Argün, 2017) (see Fig. 1). Steen-Utheim and Foldness (2018) emphasize that social constructivism provides a useful framework for examining engagement in FL, and FL should be considered a dynamic and interactive psychosocial process.

As mentioned before, the present study uses the definition of engagement offered by Fredricks et al. (2004), enriched by engagement indicators adapted from the first author's research study (see Table 1). Cevikbas (2018) determined the engagement indicators by reviewing existing studies in the literature that focus on the conceptualization of engagement (e.g. Appleton et al., 2008; Christenson et al., 2012; Fredricks et al., 2004, 2016). This rich set of indicators is useful for measuring student engagement. Data is categorized based on this classification of its dimensions (behavioral, cognitive, and emotional).

Table 1 Indicators of student engagement

\begin{tabular}{lll}
\hline Engagement & Indicators & \\
\hline Behavioral & Persistence & Asking and replying to questions \\
& Staying on task & Request for support and feedback \\
& Expending effort & Interaction with teachers and peers \\
& Getting high grades & Participation in discussions and group work \\
& Preparation before class hours & Avoidance of disruptive behavior/misbehavior \\
Cognitive & Thinking aloud & Self-monitoring and self-assessment \\
& Planning to learn & Trying to be a master in mathematics \\
& Preferring hard tasks & Being aware of the learning goals \\
& Proving and disproving & Researching for more information \\
& Independent working style & Noticing mistakes and correcting them \\
& Making evaluative comments & Making connections between learning topics \\
& Solving problems different ways & Remembering and applying previous learning \\
& Interest & Satisfaction \\
& Comfort & Eagerness, willingness \\
& Happiness & Feeling of responsibility for learning \\
& Enthusiasm & Self-confidence, feeling of sufficiency \\
& Enjoyment & Learning motivation and concentration \\
\hline
\end{tabular}


Since it is necessary to identify both intrinsic and extrinsic indicators of engagement in order to comprehensively examine the concept of engagement, we adopted a variety of engagement indicators as well as different data sources (i.e. students and teacher) and data collection methods (i.e. classroom observations, open-ended questionnaires, semi-structured teacher and student interviews, student diaries, audio recordings, and video recordings). These are described in the following section.

\section{Methodological Approach}

\section{Research Design}

This study was designed as an exploratory case study using qualitative research methods, which are particularly appropriate for attaining insight into the development and interaction of different types of student (dis-)engagement in the classroom (Fredricks et al., 2004). Case studies allow researchers to examine student engagement inductively by recording details about students' classroom interactions and activities (Chapman, 2003). Furthermore, by using case studies, researchers gather information about bounded systems through multiple data sources (Creswell, 2013). Bounded systems are systems whose limits are clearly defined, such as an individual student or teacher, a single classroom or school, or an innovative program. In this study, the bounded system (case) is a single upper secondary mathematics classroom, and we focused on students' behavioral, cognitive, and emotional engagement.

\section{Participants}

The study participants comprised 33 (17 female, 16 male) 10th-grade students at a public high school in Turkey and their mathematics teacher. Students were from medium socio-economic backgrounds and lived in an urban area. They were accustomed to learning mathematics through lecture-based instruction. Azra (pseudonym), the teacher, participated voluntarily in this research. She had six years' professional experience as a high school mathematics teacher and two weeks' FL experience from the pilot study for this research. In her usual mathematics teaching, she mainly used direct instruction. Furthermore, she was a PhD candidate and had obtained a master's degree in the fields of mathematics education.

To qualify as participants of the current study, students and the mathematics teacher needed to satisfy the following criteria.

(1) Teaching strategy (for the teacher): The teacher teaches at least one secondary mathematics classroom and adopts non-FL approach such as lecture-based teaching strategy. However, the teacher must agree to flip the mathematics teaching as we aimed to make comparisons between FL and non-FL approaches, and investigate the role of FL within student engagement.

(2) Voluntary participation: Voluntary participation was determined as a criterion as this is one of the major principles of research ethics. 
(3) Technical requirements: All participants need to have at least one mobile device (e.g. smartphone, tablet PC, or computer) with a stable Internet connection at home. It is one of the basic requirements to perform pre-class FL activities such as watching videos, being active in the online learning platform (in this case Edmodo), accessing online resources, or communicating with one another outside the class time.

(4) Self-expression: For the selection of the interviewed students, classroom observations and Azra's evaluation were used. Eight students who were willing to express themselves verbally about mathematics teaching were recruited for the semi-structured individual interviews.

\section{Data Collection and Procedure}

The data were gathered through classroom observations, students' diaries and questionnaires, student and teacher interviews, and audio-video recordings. A wide range of data were sampled and used to avoid systematic faults and to eliminate inconsistencies (Maxwell, 2013). The research process comprised four steps: (1) a two-week pilot study, (2) a two-week non-FL implementation before FL interventions, (3) a four-week FL implementation, and (4) a two-week non-FL implementation after FL interventions. This structure facilitated the comparison of student engagement in FL and non-FL settings.

In the first step, a two-week pilot study (12 course hours) was conducted among 35 high school students who differed from the main study's participants to allow the teacher to gain experience in FL implementation and develop our FL design.

In the second step, we did not interfere with the existing teaching and learning environment but simply observed Azra's teaching approach and students' learning activities for two weeks (12 course hours) to identify indicators of student engagement and Azra's teaching strategy in a non-FL setting. We compiled a checklist of behavioral, cognitive, and emotional engagement indicators for use in classroom observations. Azra's and the students' classroom activities were recorded by a video camera located in the back-right corner of the classroom. The framing of the video camera was set to cover the entire class. At the beginning of this step, students were given diary notebooks and asked to record "their experiences of learning mathematics in FL and non-FL settings" and "their thoughts about the role of FL in engagement". Students recorded diaries at home after every mathematics lesson during the second, third, and fourth steps of the research implementation. The concept of engagement (Fredricks et al., 2004) with its dimensions and indicators was introduced to the students by Azra and the privacy of the writings was ensured. At the end of the implementations, an online draw was carried out and a few mathematics books were gifted. In order to keep students' writing motivation alive during the FL and non-FL implementations, online draws were hold after all research implementations. Overall, the diaries were a crucial data source as they provided insight into students' learning experiences and their engagement in non-FL and FL environments. 
Table 2 Overview of the FL design

\begin{tabular}{lll}
\hline Environment & Tasks and activities & Time \\
\hline Out-of-class & $\bullet$ Watching lecture videos by students & $\bullet 10-20$ min $^{*}$ \\
& $\bullet$ Taking notes from the videos by students & $\bullet 5-10$ min \\
& $\bullet$ Q\&A on the content of videos (teachers or students can ask and & $\bullet$ Flexible \\
& answer questions on LMSs before the class hours) & $\bullet$ Flexible \\
& - Searching sources for getting more information & \\
& $\bullet$ A brief explanation about the topic covered in the videos & $\bullet 5$ min \\
In-class $^{* *}$ & $\bullet$ Q\&A sessions on the new topics & $\bullet 5-10$ min \\
& $\bullet$ Performing active learning activities & $\bullet 20-25$ min \\
& $\bullet$ Giving information about the next topic by teacher & $\bullet 3-5$ min \\
\hline
\end{tabular}

Note. ${ }^{*}$ Per each video, ${ }^{* *}$ in-class time is considered over 40 min for a lesson.

In the third step, the classroom setting was flipped by Azra for four weeks (24 course hours) according to the four pillars of FL pedagogy offered by FLN (2014) and the FL design introduced below in Table 2. The students' and Azra's teaching and learning activities were observed in an FL setting using the same checklist of engagement indicators and video-recorded to gather data on student engagement, as in a non-FL environment. In the FL setting, Azra benefitted from digital technologies such as GeoGebra and materials from the Internet, Edmodo, Khan Academy, YouTube, and a smartboard to transform her teaching. She shared seven lecture videos in a virtual classroom supported by Edmodo and then guided students in both individual and group activities in the classroom.

Students in the FL performed new tasks both outside and inside the class, including using Edmodo, watching lecture videos, seeking additional information, participating in question-answer and discussion sessions, problem-solving activities, and collaborative group work. Their comments and sharings on Edmodo were saved via screenshots, and conversations among students working in groups were voicerecorded. At the end of the second and fourth weeks of the FL implementation, students were given two graded quizzes.

In the final step, we conducted observations for two weeks (12 course hours) in the same classroom and used video recordings to investigate the classroom atmosphere and students' activities after FL interventions. At the end of this step, we distributed an open-ended questionnaire to the students to gather information about their engagement in both the FL and non-FL environments. Then, we selected students for the interviews based on the teacher's recommendation and the students' answers in the questionnaires and conducted semi-structured interviews to determine the influence of FL on student engagement. The interviews supported identifying the intrinsic indicators of engagement as well as extrinsic indicators.

These interviews, each lasting about one hour, were conducted with Azra and eight participating students-S1, S2, S3, S4, S5, S6, S7, S8. Figure 2 visualizes the data collection process of the study. 


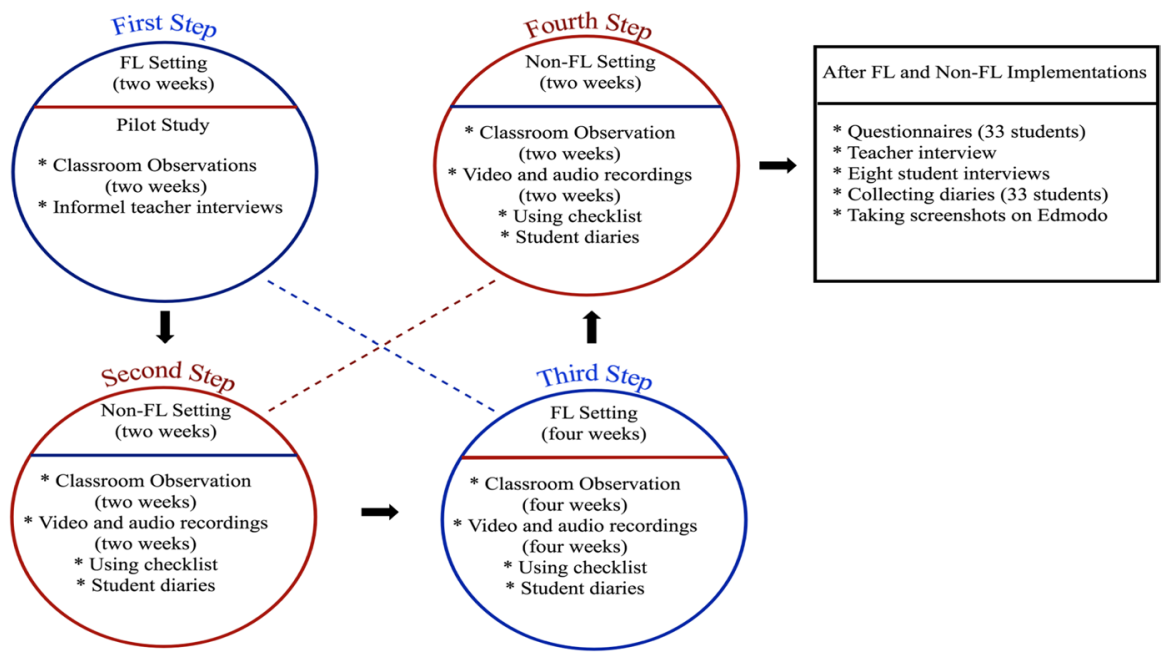

Fig. 2 Data collection process of the study

\section{Design of the Flipped Learning Approach}

In this study, we used the FLN's (2014) definition of FL as a guiding structure for the study design (an overview of the FL design used in the present study is presented in Table 2). This design is not limited to the exchange of homework and schoolwork; it also creates a flexible and interactive learning space for students both inside and outside the classroom with the help of digital technologies. In this structure, students had to perform pre-class as well as in-class tasks and construct their knowledge individually and socially.

The tasks and learning materials, including the used lecture videos, worksheets, and problem-solving activities, were developed by Azra with the support of the authors in accordance with FL implementations as this is important for the credibility and persuasiveness of the videos Azra actively participated in the content-creation processes by using content-related books, lecture notes, videos from Khan Academy, and YouTube as sources, and she created her own lecture videos. Moreover, two separate virtual classrooms were created using Edmodo LMS for the pilot study and the main study, and an Edmodo user guide was prepared and distributed to inform the participating students how to access those classrooms.

\section{Teaching Design Within the Non-flipped Learning Approach}

To better understand the results of our study, we describe shortly the teaching pattern of the non-FL design used by Azra focusing the major differences between her teaching pattern in FL and non-FL approaches. Azra's teaching approach in traditional non-FL was characterized by a lecturing style, with several examples given by the teacher at the blackboard (teacher's role) with students listening and 
Table 3 Overview of the non-FL design

\begin{tabular}{lll}
\hline Environment & Tasks and activities & Time \\
\hline Out-of-class & $\begin{array}{l}\text { Unstructured individual student } \\
\text { work }\end{array}$ & Flexible \\
In-class & Warm up activities & $5 \mathrm{~min}$ \\
& Lecturing & $25 \mathrm{~min}$ \\
& Q\&A sessions & $10 \mathrm{~min}$ \\
\hline
\end{tabular}

taking notes (students' role). As she taught mathematics at a public high school, she followed the standard textbooks, which had been approved by the Government. She did not create technologically rich and interactive student-centered learning environments or supported problem-solving activities. Table 3 gives an overview of the non-FL design used by Azra.

\section{Data Analysis}

Our analysis focused on student engagement in flipped and non-flipped mathematics settings. In order to overcome the problems of measuring student engagement, multiple data sources and robust engagement indicators were employed. The data were gathered through teacher and student interviews, classroom observations, audio and video recordings, student questionnaires, and student diaries.

The 24 video recordings and the 33 audio recordings (9 recordings from the interviews and 24 recordings from the classroom) were transcribed verbatim and we reviewed these transcripts as well as the checklists of the engagement indicators gathered through observations, student diaries, and open-ended questionnaires. Then, the data were categorized based on the conceptual structure of engagement as a meta-construct with its three components (behavioral, emotional, and cognitive). We encoded the data according to the engagement indicators and used Table 1 as a coding manual; then, the data were interpreted using the perspective of social constructivism.

Concerning the first RQ, we performed a content analysis to determine students' mathematics learning experiences in non-FL and FL approaches. Then, for the second RQ, we employed a thematic analysis to identify the separate three components of engagement in FL and non-FL settings (Miles \& Huberman, 1994). After the coding process, we synthesized the data into three themes: (1) behavioral engagement in FL and non-FL approaches, (2) emotional engagement in FL and non-FL approaches, and (3) cognitive engagement in FL and non-FL approaches.

\section{Examples of Coding Manual and Interpretation of the Data}

Table 4 presents a translated example of the coding manual from student interviews, which we interpreted afterwards with reference to this specific student (S2).

We identified six separate codes as indicators of engagement in this example: eagerness/willingness, interest, comfort, happiness, asking questions, and expending 
Table 4 Examples of coding regarding student engagement

Text

Codes/categories

Researcher: What do you think about your own engagement in the non-flipped mathematics classroom?

S2: To be honest, I was reluctant, because lessons were not interesting...

-eagerness (EE), interest (EE)

For example, when I did not understand something,

I could not ask any questions in the classroom, because I felt ashamed and we -asking question did not have enough time for it ...

(BE), comfort (EE)

I can ask the teacher a number of questions in FL, and +asking question (BE)

I spent a lot of energy learning topics in mathematics and achieved this. Hence, I felt so happy in FL ...

+ expending effort

(BE), happiness (EE)

Note. $B E$, behavioral engagement; $E E$, emotional engagement; “-”, negative code; “+”, positive code.

effort. Eagerness, interest, happiness, and comfort were coded under the emotional engagement category; asking questions and expending effort were added to behavioral engagement. These codes implied that S2 was less emotionally engaged in nonFL. She was not eager to learn mathematics in this context due to the unstimulating teaching mode. She said that she had felt ashamed to ask the teacher questions in a non-FL approach. Our observation notes confirmed this feeling in S2, who reported that when someone made a mistake in lessons, some of the students laughed and mocked them. The non-FL setting, unlike FL, might make students emotionally passive, as in this case. S2 stated that she could not ask any questions in non-FL since she felt ashamed. This result implied that emotional disengagement of S2 is interrelated with her behavioral disengagement in non-FL. Our observations provided an evidence for this claim that she did not ask or reply to any questions and avoided interaction with others in the non-FL. From the social constructivist perspective, it can be said that a non-FL setting impeded interactive learning and weakened student-teacher and student-student communication.

Measuring time-on-task Another example of analysis concerns measuring S2's time-on-task based on her classroom activities. An ordinary Turkish mathematics lesson takes $40 \mathrm{~min}$ and each implementation of research (i.e. FL and non-FL) took 960 min. $t_{\mathrm{FL}}$ means average time-on-task in a flipped lesson and $\mathrm{t}_{\mathrm{non}-\mathrm{FL}}$ means average time-on-task in a non-flipped lesson. Time-off-task corresponds to the time students spend listening to music, looking out the window, having conversations, playing games, looking at smartphones, snoozing, etc.

$$
\begin{aligned}
& \mathrm{t}_{\mathrm{FL}}=(24 \times 40-\text { totaltime }- \text { off }- \text { task }) / 24=(960-504) / 24=(456 / 24)=19 \text { minutes } \\
& \mathrm{t}_{\text {non-FL }}=(24 \times 40-\text { total time }- \text { off }- \text { task }) / 24=(960-288) / 24=(672 / 24)=28 \text { minutes }
\end{aligned}
$$

The calculations showed that S2's average time-on-task in FL was considerably longer than in non-FL. 


\section{Validity and Reliability of the Analysis}

After coding was performed, the frequency of the codes and quotations supporting the results of the study were identified. Double coding (of about $25 \%$ of the data) was performed by a researcher who had a doctoral degree in mathematics education for checking the codes of student engagement. Intercoder reliability was calculated using the formula suggested by Miles and Huberman (1994) and was found to be $93 \%$, indicating that the coding system was sufficiently reliable (Creswell, 2013). All codes identified as inconsistent were examined and discussed until full agreement was achieved. Then, the results were mirrored to the participants, i.e. the research report-more specifically, the transcribed and interpreted version of the interviews - was presented to Azra and the eight interviewed students for confirmation of the results. All nine interviewed participants agreed on the reported results.

\section{Results of the Study}

We systematized our results under three main categories: (1) behavioral engagement, (2) emotional engagement, and (3) cognitive engagement, and summarized the key results of this section at the end.

\section{Behavioral Engagement in FL and Non-FL Approaches}

Concerning the first RQ, results indicate that FL changed the participant students' in-class and out-of-class mathematics learning behavior. Students learned mathematics not also individually but also socially in an interactive FL environment. Regarding the second RQ, we found that FL promoted most participating students' behavioral engagement. In the following seven paragraphs, we illustrate the details about students' behavioral engagement in FL and non-FL environments.

\section{Pre-class Preparations}

An analysis of the self-reported data from interviews, questionnaires, and diaries demonstrated that students did not make any preparations in non-FL before class hours for the new topic in contrast, 25 students reported that they regularly prepared for the flipped lessons. We observed that Azra, in accordance with the Turkish government's current policy, gave no homework to her students in non-FL approach, and students confirmed in the interviews that they performed no pre-or post-class tasks or activities there. However, in FL most students watched videos, took notes, participated in Q\&A sessions on Edmodo, and used the Internet to access additional information about the new topics. All videos were watched by 23 of the 33 students, with 10 students skipping some lecture videos in FL implementation-three students did not watch any videos, five students watched half of the videos, and two students skipped the last one. 


\section{Asking and Replying to Questions}

All participants $(n=33)$ stated that they could not ask enough questions in mathematics lessons in non-FL approach, in FL mode they had the chance to ask all their questions to Azra or peers. We could confirm this result by classroom observations and video recordings showing that students in FL could ask questions to Azra and peers in the classroom or outside the classroom via Edmodo, even if they had skipped the lecture videos. They attempted to respond to their peers' questions and to directly ask their teacher questions in class whenever they wished. Based on the classroom observations and video analysis, we determined that, before the teaching experiment and usage of Edmodo, participating students asked 5-7 questions, when a non-FL approach was applied, in the FL approach students asked 8-14 questions on Edmodo, and 33-45 questions in the classroom.

\section{Feedback and Scaffolding}

According to the self-reported data from interviews, questionnaires, and diaries, 29 participants claimed that they had received more feedback and teacher support in FL than in non-FL mode. Our observations and video recordings confirmed that Azra provided more feedback and scaffolding in FL (feedback; 34-42 times; scaffolding 5-10 times) than in non-FL (feedback; 5-8 times; scaffolding very rare), in accordance to the increasing number of student questions in FL. In FL setting, she could offer her students timely support through feedback and scaffolding with the advantage of additional time for interactive activities in FL environment. This teaching behavior contrasted strongly with non-FL, wherein she could only provide feedback at the end of the lessons after having introduced the new content. The following statements taken from students' learning diaries and teacher interviews (all verbatim quotations were translated from Turkish into English by the first author) support these results:

I asked Azra many questions during the lessons. She answered all of my questions, and I could receive feedback and support whenever I wanted. In non-FL, we did not have time to ask questions, and we were not able to ask about the things that we could not grasp. Normally, 8-10 students engaged in non-FL, but in FL, most of us engaged in mathematics. (S2, from the student diary) FL promoted students' engagement; I helped them and gave feedback one by one throughout the whole FL implementation process. They asked me everything, but it was tiring for me. (Azra, from the teacher interview)

\section{Time-on-Task}

The results of the observations and particularly the video analysis demonstrated that, in a 40-min lesson, the eight students who were interviewed stayed on-task for approximately 15-24 min in in non-FL mode and for 23-32 min in the FL mode. We derived the time-on-task for these eight students as described in the method part. 
Overall, the results show the strong influence of FL classrooms on the engagement of the students apparent in their time-on-task behavior.

\section{Learning Effort and Grades}

In the interviews and diaries, most students $(n=28)$ stated that they invested considerable effort in learning topics both at home and in class in FL setting. Increased time-on-task as a result of FL interventions confirmed that they had invested more energy in learning mathematics. In this study, we did not aim to specifically measure the effect of FL on achievement. However, 19 participant students reported that FL improved their mathematics grades, which was supported by the results of their exam scores. Azra conducted one compulsory exam in the second phase of the research (non-FL setting) and two exams in the third phase of the research study (FL setting); the results point out that the grades of 17 students in FL exams were higher than their grades in non-FL exam. The following quote by a student developed possible explanations.

My first exam was bad in the usual class. I did not study for it and I did not deal with the mathematical concepts and problems in most usual math classes ... In FL, I was always on course, and I tried to do the activities given to us again at home. I did all those activities, and I have higher scores. (S5, from student interview and open-ended questionnaire)

\section{Group Work, Interaction, and Discussions}

In diaries, interviews, and questionnaires, participating students reported that FL encouraged them to attend the discussion groups to work on mathematical tasks collaboratively $(n=27)$ and FL substantially increased their interaction with the teacher and peers $(n=33)$. We observed that video lectures freed up class hours for students to participate in active learning activities in FL such as problem-solving, mathematical modeling, and hands-on activities that were not covered in Azra's usual teaching approach. In particular, students experienced participating in collaborative group work such as think-pair-share and snowballing in FL-for examples of students' collaborative group work, see Cevikbas and Kaiser (2020). We observed that students also participated in inquiry-based discussion activities in FL implementations with their teacher and their peers, focusing on the questions "What is the degree of the zero polynomial? What is the difference between polynomials and functions? What does polynomial function mean? Can every polynomial be divided?".

\section{Disruptive Behaviors}

In this study, we observed all students in the FL and non-FL designs of the study and noted student absences. The school absence rate was about $17 \%$ in non-FL and $5 \%$ during the FL intervention, and class lateness decreased from 11 to $2 \%$ with FL intervention. Since the participants were more involved in mathematical tasks and the teacher allocated time to help students perform the activities rather than simply 
writing on the board, a decrease could be observed in disruptive behaviors (e.g. playing games on smartphones, making noise, chewing gum, interrupting mathematics activities by talking about irrelevant topics, walking around the classroom) in FL model. According to the analysis of self-reported data, 15 students claimed that FL encouraged them to avoid disruptive behaviors in mathematics lessons; the remaining 18 students stated that FL did not have an effect on their disruptive behaviors. Additionally, as a negative result, it was found out that 10 students did not fulfill their pre-class duties regularly and therefore struggled with the mathematical problems and in-class tasks in FL.

\section{Emotional Engagement in FL and Non-FL Approaches}

Concerning the first RQ, we found that most students $(n=28)$ were satisfied with learning mathematics in FL environment and had positive emotions about FL pedagogy. Regarding the second RQ, the results of the analysis revealed that FL positively contributed to the emotional engagement of the students with the exception of a few students, who had trouble in being accustomed to the FL structure.

An analysis of the data from interviews, questionnaires, and student diaries indicated that most of the participating students had greater emotional engagement in mathematics in FL. These results are summarized in Table 5 (percentages were calculated on the sample of 33 participant students), which indicates the students' thoughts and feelings about the role of FL in their emotional engagement and change in engagement by FL intervention.

Most students reported that they completed learning tasks more enthusiastically in FL $(n=28)$ and their learning concentration $(n=21)$, motivation $(n=20)$, eagerness $(n=20)$, responsibility $(n=21)$, and interest $(n=17)$ increased during FL owing to the videos, Edmodo, collaborative group work, prompt questions, and inquiry-based classroom activities. They stated that they were happy

Table 5 Change in students' emotional engagement through FL intervention

\begin{tabular}{|c|c|c|c|c|c|c|}
\hline \multirow[t]{2}{*}{ Emotional engagement indicators } & \multicolumn{2}{|c|}{ Increase } & \multicolumn{2}{|c|}{ Decrease } & \multicolumn{2}{|c|}{$\begin{array}{l}\text { No } \\
\text { change }\end{array}$} \\
\hline & $n$ & $\%$ & $n$ & $\%$ & $n$ & $\%$ \\
\hline Enthusiasm & 28 & 85 & 1 & 3 & 4 & 12 \\
\hline Enjoyment & 22 & 67 & 2 & 6 & 9 & 27 \\
\hline Learning concentration & 21 & 64 & 3 & 9 & 9 & 27 \\
\hline Feeling of responsibility for learning & 21 & 64 & 1 & 3 & 11 & 33 \\
\hline Happiness & 20 & 61 & 3 & 9 & 10 & 30 \\
\hline Eagerness to learn mathematics & 20 & 61 & 2 & 6 & 11 & 33 \\
\hline Learning motivation & 20 & 61 & 1 & 3 & 12 & 36 \\
\hline Comfort when learning mathematics & 20 & 61 & 5 & 15 & 8 & 24 \\
\hline Satisfaction with learning mathematics & 19 & 58 & 1 & 3 & 13 & 39 \\
\hline Self-confidence in mathematics & 18 & 55 & 3 & 9 & 12 & 36 \\
\hline Feeling competent in mathematics & 18 & 55 & 5 & 15 & 10 & 30 \\
\hline Mathematics learning interest & 17 & 52 & 3 & 9 & 13 & 39 \\
\hline
\end{tabular}


$(n=20)$ and enjoyed $(n=22)$ participating in problem-solving activities within the FL structure. According to most of the students' statements, they felt competent in mathematics $(n=18)$ as well as comfortable $(n=20)$ and satisfied $(n=19)$ with the FL learning experience due to its flexibility with respect to learning time and location. They reported that FL interventions supported their self-confidence $(n=18)$. Exemplarily, we share the thoughts and feelings about the FL experience by $\mathrm{S} 3$ in a conversation with Azra as follows:

...Watching videos on the Internet draws all of our attention. It is more entertaining. The use of Edmodo and the lecture videos has increased my interest in the mathematics course, and I enjoyed learning mathematics a lot in FL. I want to continue learning math in FL. (S3, obtained from classroom observations and the video recordings)

Further support for these findings on emotional engagement emerged from the interviews and diaries below. S7 expressed that she felt bored in non-FL, but not in FL and she liked learning mathematics in FL. S8 emphasized that FL provided her opportunity to interact with Azra and peers and helped her to feel comfortable in mathematics lessons. Azra confirmed that most students liked FL, but she added that some students, particularly passive students in learning activities, were not accustomed to the new learning responsibilities in FL. These results implied that different learning settings may affect students' emotional engagement in mathematics lessons differently, although they learn mathematics with the same teacher.

Most of my students liked FL. Some students who did not take responsibility for their own learning in non-FL could not be very active in FL. This may be attributed to the fact that they had become used to the direct instruction technique over the years. In FL, students took more responsibility for their own learning. I think this is the FL's biggest role on them. (Azra, from teacher interview)

In the ordinary class, everything is standard, only a few students engage in the class. Because those students try to catch the teacher's eye, the class becomes so boring. So, we get bored and think that the teacher only cares about those students. However, in the FL, the teacher cares about everyone in the class and no one gets bored. I have started to like mathematics much more in the FL. (S7, from student interview)

For instance, I could not tell the teacher whether my solution was right or wrong when I solved the question in the traditional class. I was shy in the class, and everyone was shy like me except for a few ones. But in the FL, I can say the answer comfortably and without hesitation when the teacher asks a question, even if the answer is wrong. Since I am comfortable in the FL, my self-confidence in mathematics has increased. (S8, from student diary) 
However, three of the participants reported difficulties in adapting to the FL environment and new tasks, such as watching videos, participating in discussion sessions, and performing group work. Those participants declared that they were satisfied with the lecture-based approach adopted by the teacher in the usual classroom and that they liked passively listening to their teacher's explanations and taking notes. They reported being disconcerted that the teacher did not use the lecturing method and that they had to take responsibility for their own learning. Hence, they would prefer to learn mathematics in the non-FL situation, in contrast to the other participants. These three students including the teacher Azra preferred the non-FL approach, but they wanted non-flipped mathematics classes to incorporate lecture videos. Additionally, five students stated that they felt uneasy and stressed, especially at the beginning of the FL interventions, owing to changes in their learning routine. They expressed concerns about their inability to comprehend the topics in the FL setting.

\section{Cognitive Engagement in FL and Non-FL Approaches}

Concerning the first RQ, the students stated that FL offered them an eye-opening and rich learning experience both outside and inside the classroom. Regarding the second RQ, our analysis showed that most participating students $(n=28)$ reported that they had greater cognitive engagement in flipped mathematics classroom. These results are summarized in Table 6, which indicates the students' reports about the role of FL in their cognitive engagement as positive, negative, or no change based on the cognitive engagement indicators.

Table 6 Change in students' cognitive engagement through FL intervention

\begin{tabular}{|c|c|c|c|c|c|c|}
\hline \multirow[t]{2}{*}{ Cognitive engagement indicators } & \multicolumn{2}{|c|}{ Positive } & \multicolumn{2}{|c|}{ Negative } & \multicolumn{2}{|c|}{ No change } \\
\hline & $n$ & $\%$ & $n$ & $\%$ & $n$ & $\%$ \\
\hline Solving problems different ways & 29 & 88 & 0 & 0 & 4 & 12 \\
\hline Thinking aloud & 26 & 79 & 2 & 6 & 5 & 15 \\
\hline Remembering and applying previous learning & 25 & 76 & 0 & 0 & 8 & 24 \\
\hline Planning to learn & 23 & 70 & 3 & 9 & 7 & 21 \\
\hline Trying to be master in mathematics & 23 & 70 & 1 & 3 & 9 & 27 \\
\hline Proving and disproving & 23 & 70 & 1 & 3 & 9 & 27 \\
\hline Researching for more information & 22 & 67 & 5 & 15 & 6 & 18 \\
\hline Independent working style & 22 & 67 & 5 & 15 & 6 & 18 \\
\hline Making evaluative comments & 22 & 67 & 2 & 6 & 9 & 27 \\
\hline Being aware of the learning goals & 20 & 61 & 0 & 0 & 13 & 39 \\
\hline Making connections between learning topics & 20 & 61 & 0 & 0 & 13 & 39 \\
\hline Self-monitoring and self-assessment & 19 & 58 & 0 & 0 & 14 & 42 \\
\hline Noticing mistakes and correcting them & 17 & 52 & 0 & 0 & 16 & 48 \\
\hline Preferring hard tasks and problems & 13 & 39 & 1 & 3 & 19 & 58 \\
\hline
\end{tabular}


A high number of students $(n=29)$ reported that they had attempted to create authentic problem-solving strategies after the FL intervention and that this approach had improved their flexibility in problem-solving. We observed that it became possible for students to solve various mathematical problems during FL lessons, since lectures were offered through explanatory videos. In contrast, different types of mathematical problems, such as word problems and real-world problems, were not studied in non-FL setting; generally, 5-6 easier problems and examples were provided. Thus, the participants were not involved in high-level mathematical problems and did not work on developing authentic problem-solving strategies there.

I can find different strategies while solving problems in the FL, which has helped me a lot. I learned to solve problems by addressing what I learned from different perspectives. (S7, from student diary)

According to analysis of the self-reported data, most students $(n=26)$ claimed that FL classrooms encouraged them to think aloud in mathematics lessons, and our observations confirmed that most students $(n=25)$ made evaluative comments and exchanged ideas with one another, both outside the classroom through the LMS Edmodo and in flipped lessons, contrary to non-flipped lessons. More than half of the students $(n=19)$ highlighted that by using the features offered by Edmodo, they were able to follow their learning progress as the LMS saves students' actions and creates learning progression reports. Therefore, they had the opportunity to assess their own performance and learn about their peers' learning approaches during group work in FL. About half of the students $(n=17)$ stated that they could notice their or peers' mistakes and corrected them in FL activities such as Edmodo discussions and group work.

We participated in group work in the FL and did individual activities as well.

I could share my thoughts in group work and via Edmodo. I noticed my mistakes, and sometimes my friends' mistakes, and corrected them. I could carefully observe what my friends did and how they solved the math problems in the FL. (S8, from student diary)

A high number of participants reported that FL encouraged them to prove their arguments or disprove opposing arguments through discussion sessions $(n=23)$ and help them make connections between different learning topics $(n=20)$. According to students' self-reports, the structure of FL supported students in remembering and applying previous learning $(n=22)$. We observed that students were able to establish connections between different topics with the help of discussion sessions in FL and could better understand new topics using the knowledge they had already gained:

Azra: ... We learned functions in the previous unit, now we're going to learn polynomials, then quadratic equations. Do you think there is a link between these topics?

Student 10: Functions with polynomials are very similar topics.

Azra: How? 
Student 10: If we understand the functions well, we can also understand polynomials. Because every polynomial is a function; and a polynomial is a special form of function.

Student 17: But not every function is polynomial; we discussed this (in FL).

Student 32: We can also benefit from the polynomials in the next topic, which is while solving equations. It is useful to find the root of the equations. These topics are closely interrelated with each other... (from classroom conservations in FL discussion sessions)

We prepared for the topic before and watched the lecture videos again and again in the FL. We did not forget previous topics and tried to connect the new topic with the previous ones. In this way, we could understand the new topic easily. (S3, from student interview)

A number of students mentioned that FL encouraged them to master mathematics $(n=23)$ and to use various sources (the Internet, books, textbooks, etc.) to retrieve new information $(n=22)$, and to solve difficult problems in FL $(n=13)$. Students' learning efforts supported students' intentions to gain a deeper understanding and mastery of complex mathematical problems.

For example, while I was making mistakes in even simple mathematical calculations in the ordinary class, I did not make mistakes anymore in the FL. I investigated many topics at home and worked hard to learn in the best way in the FL. It made me better in mathematics. (S7, from student interview)

The classroom conversations and student interviews indicated that in non-FL format some participants $(n=20)$ were unaware of learning goals and why they had learned mathematics while others were unsure about what they had learned. Our classroom observations and video recordings in non-FL pointed out that most of the students (92\%) simply copied down information that was written on the blackboard unquestioningly. About half of the students reported in the learning diaries and interviews that they found mathematics learning meaningless before FL intervention, and they considered themselves unsuccessful in relating things they had previously learned to what they were learning currently $(n=20)$. However, in FL, since most of the students $(76 \%)$ watched the lecture videos, prepared themselves for the lessons before coming to the classroom, and they were aware of what they learned and had a plan for their own learning. Additionally, according to students' self-report, FL improved not only their collaborative working skills but also independent working abilities $(n=22)$ and clarified their learning goals $(n=20)$.

We did not perform such activities (problem-solving, modeling, hands-on, inquiring, group work, etc.) in the usual class, but we just wrote the things on the board. I find the FL different, namely, eye-opening. I understood the importance of polynomials and why we should learn this topic thanks to our discussions in FL. (S6, from student interview)

As a negative aspect of FL, a few students $(n=5)$ stated that particularly at the beginning of the FL implementations they could not mentally prepare themselves 
for the new learning responsibilities inherent of FL, which negatively affected their engagement.

\section{Summary of the Key Results}

The results indicated that most of the students were more engaged-behaviorally, cognitively, and emotionally - in FL than in non-FL settings. However, an important group of ten students lacked behavioral engagement in the flipped mathematics classroom, and about five of these lacked emotional and cognitive engagement in FL.

The most effective FL interventions on student engagement were reconstructed from the participants' perspectives based on their FL experiences as follows: flexible learning environment $(n=28)$, lecture videos $(n=26)$, problem-solving activities and worksheets $(n=25)$, Edmodo usage $(n=21)$, discussion sessions $(n=19)$, teacher feedback and scaffolding $(f=18)$, collaborative group work $(n=18)$, and quizzes $(n=16)$.

\section{Discussion}

The aim of this paper was to uncover participating students' mathematics learning experiences and their behavioral, cognitive, and emotional engagement in mathematics. The results of this case study are limited to a study with 33 high school students' experience in FL and non-FL settings covering 10-week implementations. The teacher was a PhD candidate and taught mathematics for six years; however, she had only two-week flipped teaching experience acquired in the pilot study. These limitations should be taken into account when interpreting the results.

Concerning the first RQ, the results indicate that FL turned the focus from teacher to students and provided rich and interactive mathematics learning experiences for the participating students. Regarding the second RQ, the results of the study pointed out that FL positively influenced most of the students' behavioral, cognitive, and emotional engagement by (1) creating interactive and flexible learning environments, (2) encouraging students to learn individually and socially, (3) providing customized guidance, and (4) fostering inquiry, discussion, and collaboration in the mathematical learning process. The most effective elements of FL reconstructed in this study came from the participants' views based on their experiences of FL as a flexible learning environment, providing lecture videos, problem-solving activities, use of learning platform (Edmodo), discussion sessions, teacher feedback and scaffolding, and collaborative group work.

In our case, FL's major contribution to engagement became manifest in the paradigm shift from behaviorism to social constructivism. However, the engagement of several students was negatively affected especially at the beginning of the FL implementations, and they had trouble in altering their learning habits and performing preclass activities, which is in line with known results about the relationship between teaching practice and students' learning behavior (Kahu, 2013). The difficulties that 
these students experience with FL may be related to the fact that they have learned mathematics for many years in a traditional way that does not involve interaction, social learning, and collaboration with peers, and they may have developed a learning habit in this direction. Although five students reported anxiety that they would not be successful in FL due to the radical change in the learning-teaching approach and student tasks, the remaining students demonstrated their willingness to engage in mathematics when opportunities and interactive learning environments were created for them. These results imply that the socially constructed learning environment and interaction played an important role in students' engagement and that teachers should be more proactive in triggering social activities in mathematics teaching.

On the one hand, our main result that FL can promote students' engagement in the secondary mathematics classroom is in line with several existing studies which approached engagement as an entity and did not explicitly focus on separate dimensions of engagement (Clark, 2015; Muir, 2017; Muir \& Geiger, 2016) or focused on only cognitive engagement (Lo \& Hew, 2020). On the other hand, this main result is inconsistent with another study (Hodgson et al., 2017) that focused exclusively on behavioral engagement. Hodgson et al.'s (2017) comparison of behavioral engagement in three FL and non-FL settings reveals that the students in two non-FL settings were more behaviorally engaged in mathematics, contrary to our result. This difference in the effect of FL on student engagement may depend on how FL classroom was designed and implemented or how engagement was conceptualized or measured. Since most existing studies did not elaborate their conceptualization of engagement clearly and as the structure of our study differs from others, it is difficult to compare our results directly with those of other studies.

In our case, most students engaged stronger in mathematics behaviorally, cognitively, and emotionally in FL than in non-FL setting. Moreover, the study has produced an interesting and open-to-interpretation result in which the number of behaviorally disengaged students (about 10) was greater than that of the emotionally and cognitively disengaged students (about five students within behaviorally disengaged 10 students) in FL. This result indicates that while some students emotionally and cognitively engaged in FL, they did not behaviorally engage in flipped mathematics classrooms. This difference may also be related to the indicators of cognitive and emotional engagement, which are naturally more internal than indicators of behavioral engagement. In any case, components of engagement are interrelated and constitute a dynamic concept.

Another interesting result reveals that engagement was found to be negatively affected, when the students perceived FL negatively. It has been determined that some students perceived FL negatively due to the emerging new pre-class learning responsibilities and had difficulty in adapting to the new learning environment. It has been revealed that students' negative perception of FL affected their motivation to fulfill their pre-class tasks and that the deficiency in performing the particular pre-class tasks also reduced their classroom engagement. For this reason, the issue of what can be done to prevent students from developing negative attitudes towards FL and to facilitate their adaptation to learn mathematics in FL needs to be investigated in future studies. 
Another important result is related to the teacher's approach to FL. The teacher reported that she preferred the traditional non-FL mode rather than FL for mathematics teaching. She declared that although FL enhanced her students' engagement, she did not aspire to continue flipping her teaching because FL demands exhausting and time consuming teaching activities. Although it is also possible to use studentcentered strategies in non-FL approaches, she did not use neither interactive strategies nor digital technologies and preferred direct instruction in her casual teaching. She based her preference on the lack of appropriate content and time for active learning activities in the classroom. Overall, the unwillingness of the teacher to flip mathematics lessons, as well as her inexperience in FL, may have affected the results of the study that are related to potential effects of FL on participating students' engagement. Moreover, FL was a new pedagogy for the participating students and a novelty effect (positive or negative) may have occurred on the results (Clark, 2015). Thus, future longitudinal studies are needed to shed more light on these problems.

\section{Conclusion}

To sum up, FL is a promising pedagogy that has the potential to play a positive role in three components of engagement (behavioral, cognitive, and emotional) as it provides learners with many possibilities while learning mathematics. To implement a successful FL, it is important to have a well-developed interactive design and to encourage social interaction in mathematics teaching and learning. In the light of our results, it becomes clear that mathematics education can benefit from FL by strengthening students' engagement in mathematics education.

Overall, we propose that future studies conduct research on engagement in FL based on a clarification of their study design and theoretical frameworks with respect to FL, the conceptualization of engagement, and the indicators of engagement so that comparisons between the different studies can be done.

Funding Open Access funding enabled and organized by Projekt DEAL.

Open Access This article is licensed under a Creative Commons Attribution 4.0 International License, which permits use, sharing, adaptation, distribution and reproduction in any medium or format, as long as you give appropriate credit to the original author(s) and the source, provide a link to the Creative Commons licence, and indicate if changes were made. The images or other third party material in this article are included in the article's Creative Commons licence, unless indicated otherwise in a credit line to the material. If material is not included in the article's Creative Commons licence and your intended use is not permitted by statutory regulation or exceeds the permitted use, you will need to obtain permission directly from the copyright holder. To view a copy of this licence, visit http://creativecommons.org/licen ses/by/4.0/.

\section{References}

Abeysekera, L., \& Dawson, P. (2015). Motivation and cognitive load in the flipped classroom: Definition, rationale and a call for research. Higher Education Research and Development, 34(1), 1-14. 
Ahmed, H. O. K. (2016). Flipped learning as a new educational paradigm: An analytical critical study. European Scientific Journal, 12(10), 417-444.

Appleton, J. J., Christenson, S. L., \& Furlong, M. J. (2008). Student engagement with school: Critical conceptual and methodological issues of the construct. Psychology in the Schools, 45(5), 369-386.

Bergmann, J. \& Sams, A. (2012). Flip your classroom: Reach every student in every class every day. ISTE.

Bond, M. (2020). Facilitating student engagement through the flipped classroom approach in K-12: A systematic review. Computers \& Education, 151, 103819.

Bredow, C. A., Roehling, P. V., Knorp, A. J., \& Sweet, A. M. (2021). To flip or not to flip? A meta-analysis of the efficacy of flipped learning in higher education. Review of Educational Review. https:// doi.org/10.3102/00346543211019122.

Cevikbas, M. (2018). Ters-yüz sınıf modeli uygulamalarına dayalı bir matematik sınıfındaki öğrenci katılım sürecinin incelenmesi [Investigation of student participation process in a mathematics classroom based on flipped classroom model applications] (Unpublished doctoral dissertation). Gazi University.

Cevikbas, M., \& Argün, Z. (2017). An innovative learning model in digital age: Flipped classroom. Journal of Education and Training Studies, 5(11), 189-200. https://doi.org/10.11114/jets.v5i11. 2322.

Cevikbas, M., \& Kaiser, G. (2020). Flipped classroom as a reform-oriented approach to teaching mathematics. ZDM - Mathematics Education, 52, 1291-1305. https://doi.org/10.1007/ s11858-020-01191-5.

Cevikbas, M., \& Kaiser, G. (2021). A systematic review on task design in dynamic and interactive mathematics learning environments (DIMLEs). Mathematics, 9(4), 399. https://doi.org/10.3390/ math9040399.

Chapman, E. (2003). Alternative approaches to assessing student engagement rates. Practical Assessment, Research \& Evaluation, 8(13), 1-10.

Christenson, S. L., Reschly, A. L., \& Wylie, C. (Eds.). (2012). Handbook of research on student engagement. Springer.

Clark, K. R. (2015). The effects of the flipped model of instruction on student engagement and performance in the secondary mathematics classroom. Journal of Educators Online, 12(1), 91-115.

Collie, R. J., Martin, A. J., Bobis, J., Way, J., \& Anderson, J. (2019). How students switch on and switch off in mathematics: Exploring patterns and predictors of (dis)engagement across middle school and high school. Educational Psychology, 39(4), 489-509.

Creswell, J. W. (2013). Qualitative inquiry research design. Choosing among five approaches. Sage.

Flipped Learning Network. (2014). The four pillars of FLIP. https://fippedlearning.org/defnition-offipped-learning/. Accessed 10 Sept 2020.

Fredricks, J. A., Blumenfeld, P. C., \& Paris, A. H. (2004). School engagement: Potential of the concept, state of the evidence. Review of Educational Research, 74, 59-109.

Fredricks, J. A., Wang, M. T., Linn, J. S., Hofkens, T. L., Sung, H., Parr, A., \& Allerton, J. (2016). Using qualitative methods to develop a survey measure of math and science engagement. Learning and Instruction, 43, 5-15.

Hodgson, T. R., Cunningham, A., McGee, D., Kinne, L., \& Murphy, T. J. (2017). Assessing behavioral engagement in flipped and non-flipped mathematics classrooms: Teacher abilities and other potential factors. International Journal of Education in Mathematics, Science and Technology, 5(4), 248-261.

Kahu, E. R. (2013). Framing student engagement in higher education. Studies in Higher Education, 38(5), 758-773.

Kuiper, S. R., Carver, R. H., Posner, M. A., \& Everson, M. G. (2015). Four perspectives on flipping the statistics classroom: Changing pedagogy to enhance student-centered learning. Primus, 25(8), 655-682.

Lage, M. J., Platt, G. J., \& Treglia, M. (2000). Inverting the classroom: A gateway to creating an inclusive learning environment. The Journal of Economic Education, 31(1), 30-43.

Lo, C. K., \& Hew, K. F. (2017). A critical review of flipped classroom challenges in K-12 education: Possible solutions and recommendations for future research. Research and Practice in Technology Enhanced Learning, 12(1), 4-26.

Lo, C. K., \& Hew, K. F. (2020). A comparison of flipped learning with gamification, traditional learning, and online independent study: The effects on students' mathematics achievement and cognitive engagement. Interactive Learning Environments, 28(4), 464-481. 
Marks, H. M. (2000). Student engagement in instructional activity: Patterns in the elementary, middle, and high school years. American Educational Research Journal, 37(1), 153-184.

Martin, A. J., Way, J., Bobis, J., \& Anderson, J. (2015). Exploring the ups and downs of mathematics engagement in the middle years of school. The Journal of Early Adolescence, 35(2), 199-244.

Maxwell, J. A. (2013). Qualitative research design: An interactive approach (3rd ed.). Sage.

Miles, M. B., \& Huberman, A. M. (1994). Qualitative data analysis (2nd ed.). Sage.

Muir, T. (2017). The enactment of a flipped classroom approach in a senior secondary mathematics class and its impact on student engagement. In B. Kaur, W. K. Ho, T. L. Toh, \& B. H. Choy (Eds.), Proceedings of the 41st Conference of the International Group for the Psychology of Mathematics Education (Vol. 3, pp. 281-288). PME.

Muir, T., \& Geiger, V. (2016). The affordances of using a flipped classroom approach in the teaching of mathematics: A case study of a grade 10 mathematics class. Mathematics Education Research Journal, 28(1), 149-171.

Newmann, F. M. (1992). Student engagement and achievement in American secondary schools. Teachers College.

O'Flaherty, J., \& Phillips, C. (2015). The use of flipped classrooms in higher education: A scoping review. The Internet and Higher Education, 25, 85-95.

Schuetz, R. L., Biancarosa, G., \& Goode, J. (2018). Is technology the answer? Investigating students' engagement in math. Journal of Research on Technology in Education, 50(4), 318-332.

Steen-Utheim, A. T., \& Foldnes, N. (2018). A qualitative investigation of student engagement in a flipped classroom. Teaching in Higher Education, 23(3), 307-324.

Vygotsky, L. S. (1978). Mind in society: The development of higher psychological processes. Harvard University Press. 